\title{
Autonomous Air Conditioning System
}

\author{
Syed Fazil Bin Farukh and M. Saleem Khan
}

\begin{abstract}
This paper presents an autonomous air conditioning control system using fuzzy time control discrete event model. The system is designed with two inputs: Temperature, humidity and two outputs: fan speed and fan spinning time. Temperature and humidity are controlled by controlling the three valves i.e. cooling valve, heating valve and humidifying valve. System takes feedback from sensors. Fuzzy time control rules are formed and simulated using the MATLAB tool box. The results obtained from the MATLAB simulation are found to be correct according to the design modeling. The work is based on fuzzy time control discrete event model and implementation of design algorithm. this research work will inanes the capability of the existing fuzzy logic control system and discusses the time control issues of digital dynamical control systems.
\end{abstract}

Index Terms-Fuzzy time control discrete event system, MATLAB simulation, air conditioning system.

\section{INTRODUCTION}

Control system has got vital industrial applications in recent times. There are numerous applications of automation controls in nature and industry e.g. inside our body food digestive system, blood circulatory system, air plain autopilot, modern transportation, communication and in manufacturing industry. Automation provides better performance, reduces the manufacturing cost and provides mass production

Fuzzy time control discrete event model is much better than fuzzy logic control (FLC) and conventional control system due to its simplicity in calculation and better performance. Fuzzy logic control is based on heuristic knowledge and deals with non probabilistic uncertainty issues [1]. Numerous system are designed using the fuzzy logic control which take numeric input and give numeric output but the controllers work on words. Although these systems are good enough in their design and performance but they do not take time into account. Time independency is their draw back. The proposed air conditioning model is designed using the fuzzy time control discrete event model [2], for which the output states are bounded with time and used to operate the plant ON or OFF for certain time period [3]-[6]. This research work provides a better design of autonomous air conditioner, due to its time dependency large amount of energy will also be conserved. The designed model itself provides a new way to design other systems based on fuzzy time control discrete event model.

Manuscript received March 5, 2013; revised April 26, 2013.

Syed Fazil Bin Farukh is with the international Islamic university Islamabad (e-mail: harisali4@ yahoo.com).

M. Saleem Khan was with GC University Lahore Pakistan (e-mail: mskgcu@yahoo.com).

\section{FuZZY Time Control Discrete EVEnt System}

Fuzzy time control discrete event system is the combination of the fuzzy time control system and the discrete event system as shown in the figure-1below.

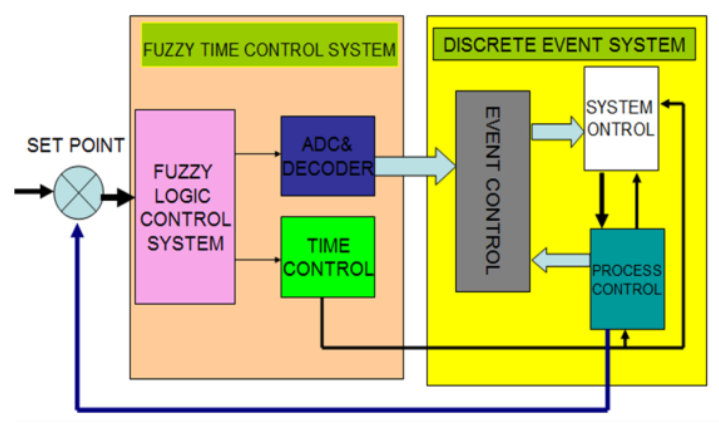

Fig. 1. Block diagram of fuzzy time control discrete event system

\section{FuZZY TIME CONTROL SySTEM}

Fuzzy logic time control system generates the output variable and output time signal. Fuzzy logic time control system sub divided into two parts; one is Generator (G), (which produce the numeric outputs) second is time control (TC), (TC produce the numeric value of time for output) [7].

\section{DiscRETE EVENT SySTEM}

In the designed modeling the Discrete event system is further subdivided in to three parts;

1) Event control

2 Process control

3) System control

1) Event control: takes input from fuzzy logic time control to generate and manage event.

2) Process control: takes inputs from system control and event control to assign a process for that event for a specific interval of time.

3) System control: controls the whole system for a specific interval of time.

After defuzzification Binary control signals and time control signals from fuzzy logic time control system are given to discrete event system which allow to pass these binary control signals to operate the plant ON or OFF for specific time period.

This air conditioning system contains two fuzzifiers, inference engine. Knowledge base along with data base, rule base and output membership functions (MF) [8], knowledge base is attached with the inference engine, two defuzzifiers and discrete event system.

Numeric inputs are given to the Fuzzifiers which converts 
these numeric inputs to the linguistic variables these linguistic variables are given to inference block where the max-min composition is applied to get four values of $\mathrm{R}$. Knowledge base receives the crisp values of input variables and give four singleton values according to the rules which are designed for system. These singleton values and values of $\mathrm{R}$ are provided to the defuzzifiers, here two defuzzifiers are used, one for output variable fan speed and other for output time control, fan spinning time [2].

After defuzzification two numeric (crisp) values of outputs are obtained one for output variable; fan speed and other for fan spinning time. Analog to digital converter(ADC) is used to convert the crisp value of fan speed into binary code and crisp value of fan spinning time are provided to the pulse strobe unit, which allow to pass binary code for a certain time. Then these binary codes are used to make active discrete event system under time constrain [9].

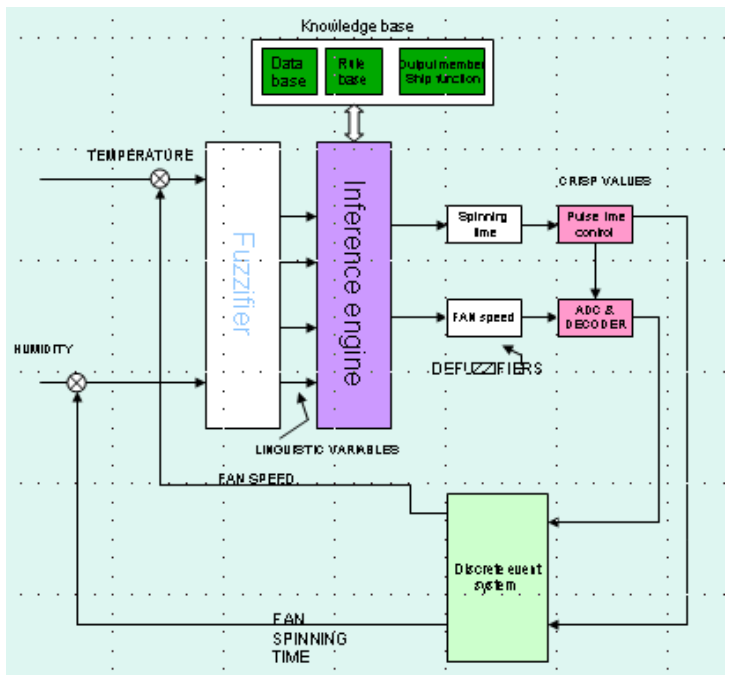

Fig. 2. Experimental arrangement of designed model .

\section{DESIGN AlgORITHEM}

The autonomies air conditioning system is design for two inputs, temperature and humidity, and two outputs; one is fan speed and the other is fan spinning time. The membership functions of input variables and there ranges are shown in the Table I and Table II.

TABLE I: INPUT MEMBERSHIP FUNCTION FOR TEMPERATURE AND THEIR

\begin{tabular}{|l|l|l|}
\hline No & $\begin{array}{l}\text { Membership } \\
\text { function(MF) }\end{array}$ & Temperature $\left({ }^{\mathbf{0}} \mathbf{C}\right)$ \\
\hline 1 & Cold & $0--12.5$ \\
\hline 2 & Cool & $0-25$ \\
\hline 3 & Normal & $12.5--37.5$ \\
\hline 4 & Warm & $25-50$ \\
\hline 5 & Hot & $37.5-50$ \\
\hline
\end{tabular}

TABLE II: INPUT MEMBERSHIP FUNCTION FOR HUMIDITY AND THEIR RANGES

\begin{tabular}{|l|l|l|}
\hline NO & $\begin{array}{l}\text { Membership } \\
\text { function(MF) }\end{array}$ & HUMIDITY \\
\hline 1 & DRY & $0 \%-25 \%$ \\
\hline 2 & JUST DRY & $0 \%-50 \%$ \\
\hline 3 & MOIST & $25 \%-75 \%$ \\
\hline 4 & JUST WET & $50 \%-100 \%$ \\
\hline 5 & WET & $75 \%-100 \%$ \\
\hline
\end{tabular}

The plot of input membership function of temperature are shown in Fig. 1 there are five membership functions i.e. $F_{1}$ [1], $F_{1}[2], F_{1}[3], F_{1}[4], F_{1}[5]$ and four regions

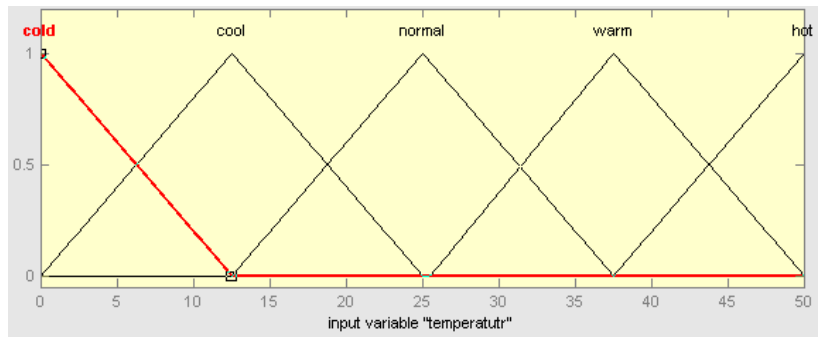

Fig. 3. Membership function plot for temperature

The plot of input membership functions for humidity are shown in Fig. 2 there are five membership functions i.e. $\mathrm{F}_{2}[1], \mathrm{F}_{2}[2], \mathrm{F}_{2}[3], \mathrm{F}_{2}[4], \mathrm{F}_{2}[5]$ there are four regions.

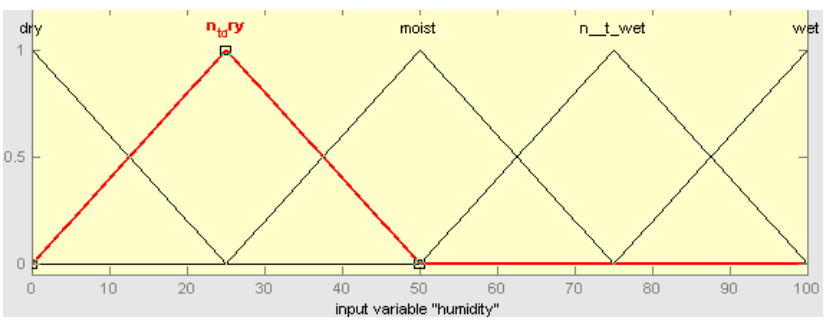

Fig. 4. Membership function plot for humidity

Two outputs their membership functions are listed in Table III.

TABLE III: OUTPUT MEMBERSHIP FUNCTION RANGESFOR FAN SPEED AND FAN SPINNING TIME

\begin{tabular}{|l|l|l|l|}
\hline $\begin{array}{l}\text { Membership } \\
\text { Functions }\end{array}$ & Ranges & Fan speed & $\begin{array}{l}\text { Fan } \\
\text { spinning } \\
\text { Time }\end{array}$ \\
\hline MF1 & $0-25$ & Stop & None \\
\hline MF2 & $0-50$ & Slow & Small \\
\hline MF3 & $25-75$ & Medium & Medium \\
\hline MF4 & $50-100$ & Fast & Long \\
\hline MF5 & $75-100$ & $\begin{array}{l}\text { Vary } \\
\text { Fast }\end{array}$ & $\begin{array}{l}\text { Very } \\
\text { Long }\end{array}$ \\
\hline
\end{tabular}

For the convenience in calculation the range values of output membership function for fan speed and fan spinning time are taken same

Plot of output membership function for fan speed and fan spinning time contains five MF,sand four regions

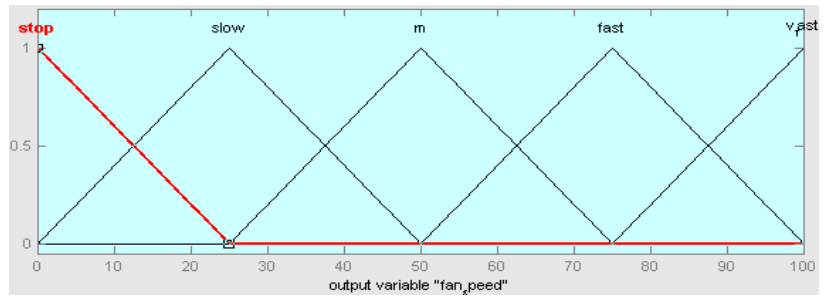

Fig. 5. Membership function plot for output variable

To verify the design model of the autonomous air conditioning system use the input fuzzy variables temperature $=22^{\circ} \mathrm{c}$ and humidity $=30 \%$ this value of temperature lies in the second half of second region and this humidity value lies in the first half of the second region.

Where the given value $22{ }^{\circ} \mathrm{C}$ of temperature maps with the MF cool and normal for which the normal is taken as $\mathrm{F}$ [1] and cool is taken as F [2] similarly the value 30 of humidity 
maps with the value MF moist and just dry for which the moist is taken as F [3] and just dry is taken as F [4]

The fuzzifier result for this proposed algorithm are shown in the Table IV.

TABLE IV: FUZZIFIER RESULTS FOR AIR CONDITIONING MODEL
\begin{tabular}{|l|l|l|l|}
\hline $\begin{array}{l}\text { Input } \\
\text { Variable }\end{array}$ & Value & $\begin{array}{l}\text { Region } \\
\text { selection }\end{array}$ & $\begin{array}{l}\text { Fuzzy set } \\
\text { Calculation }\end{array}$ \\
\hline Temperature & 22 & 2 & $\begin{array}{l}\text { F[1] }=0.24 \\
\text { F[2] }=1-\end{array}$ \\
& & & \\
& & & F[1] \\
& & & $=0.76$ \\
\hline Humidity & 30 & 2 & $\begin{array}{c}\text { F[3] }=0.2 \\
\text { F[4] }=1- \\
\end{array}$ \\
& & & F[3] \\
& & & $=0.8$ \\
\hline
\end{tabular}

Inference engine takes four inputs from fuzzifiers apply the min-AND operation and gives the four values i.e. $R_{1}, R_{2}$, $R_{3}$ and $R_{4}$ as shown in the figure below

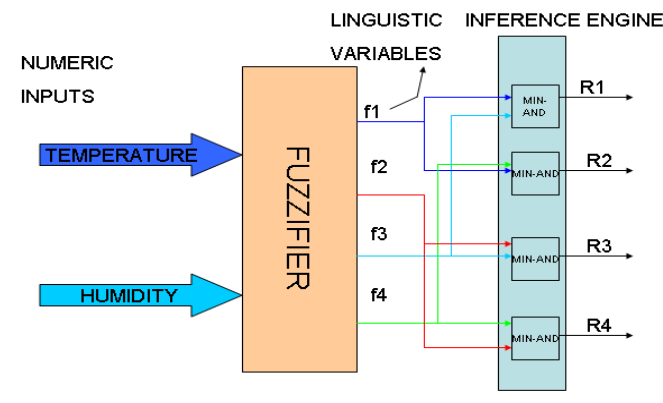

Fig. 6. Inference engine design for air conditioning model.

$$
\begin{gathered}
\mathrm{R}_{1}=F[1] \text { and } \mathrm{F}[3]=0.24 \text { and } 0.2=0.2 \\
\mathrm{R}_{2}=\mathrm{F}[1] \text { and } \mathrm{F}[4]=0.24 \text { and } 0.8=0.24 \\
\mathrm{R}_{3}=\mathrm{F}[2] \text { and } \mathrm{F}[3]=0.76 \text { and } 0.2=0.2 \\
\mathrm{R}_{4}=\mathrm{F}[2] \text { and } \mathrm{F}[4]=0.76 \text { and } 0.8=0.76
\end{gathered}
$$

In the output membership function plot there are five overlapping regions, system designed with two inputs so total twenty five rules are applied for this proposed system [6]. Which are listed in the Table V.

\begin{tabular}{|c|c|c|c|c|}
\hline \multicolumn{5}{|c|}{ TABLE V: RULES DESIGNED FOR SYSTEM } \\
\hline NO & $\begin{array}{c}\text { Tempe } \\
\text { rature }\end{array}$ & $\begin{array}{c}\text { Humidit } \\
\text { y }\end{array}$ & $\begin{array}{c}\text { Fan } \\
\text { speed }\end{array}$ & $\begin{array}{c}\text { Fan spinning } \\
\text { time }\end{array}$ \\
\hline 1 & Cold & Dry & Stop & None \\
\hline 2 & Clod & Just dry & Stop & None \\
\hline 3 & Cold & Moist & Stop & None \\
\hline 4 & Cold & Just wet & Stop & None \\
\hline 5 & Cold & Wet & Slow & Small \\
\hline 6 & Cool & Dry & Stop & None \\
\hline 7 & Cool & Just dry & Stop & None \\
\hline 8 & Cool & Moist & Stop & None \\
\hline 9 & Cool & Just wet & Slow & Small \\
\hline 10 & Cool & Wet & Slow & Small \\
\hline 11 & Normal & Dry & Slow & Small \\
\hline 12 & Normal & Just dry & Slow & Small \\
\hline 13 & Normal & Moist & Mediu & Medium \\
\hline 14 & Normal & Just wet & Mediu & Medium \\
\hline 15 & Normal & Wet & Fast & Long \\
\hline 16 & Warm & Dry & $\begin{array}{c}\text { Mediu } \\
\mathrm{m}\end{array}$ & Long \\
\hline 17 & Warm & Just dry & Fast & Long \\
\hline 18 & Warm & Moist & Fast & Long \\
\hline 19 & Warm & Just wet & Fast & Long \\
\hline
\end{tabular}

\begin{tabular}{|c|c|c|c|c|}
\hline 20 & Warm & Wet & $\begin{array}{c}\text { Very } \\
\text { fast }\end{array}$ & Long \\
\hline 21 & Hot & Dry & Fast & Long \\
\hline 22 & Hot & Just dry & $\begin{array}{c}\text { Very } \\
\text { fast }\end{array}$ & Very long \\
\hline 23 & Hot & Moist & $\begin{array}{c}\text { Very } \\
\text { fast }\end{array}$ & Very long \\
\hline 24 & Hot & Just wet & $\begin{array}{c}\text { Very } \\
\text { fast }\end{array}$ & Very long \\
\hline 25 & Hot & Wet & $\begin{array}{c}\text { Very } \\
\text { fast }\end{array}$ & Very long \\
\hline
\end{tabular}

For this proposed system out of these twenty-five rules only four rules are applied at a time for the given values input variables.

For temperature $=22^{\circ} \mathrm{C}$ and humidity $=30 \%$ the rules applied are listed in the Table VI.

TABLE VI: SELECTED RULES FOR INPUT VARIABLES

\begin{tabular}{|l|l|l|l|l|}
\hline $\begin{array}{l}\text { Rule } \\
\text { NO }\end{array}$ & $\begin{array}{l}\text { Temper } \\
\text { ature }\end{array}$ & Humidity & $\begin{array}{l}\text { Fan } \\
\text { speed }\end{array}$ & $\begin{array}{l}\text { Fan } \\
\text { spinning } \\
\text { time }\end{array}$ \\
\hline 7 & Cool & Just dry & Stop & None \\
\hline 8 & Cool & Moist & Stop & None \\
\hline 12 & Normal & Just dry & Slow & Small \\
\hline 13 & Normal & Moist & $\begin{array}{l}\text { Mediu } \\
\text { m }\end{array}$ & Medium \\
\hline
\end{tabular}

Corresponding to these four rules, rule base provides four singleton values which are listed in the Table VII.

TABLE VII: SINGLETON VALUES FOR OUTPUTS

\begin{tabular}{|c|c|c|}
\hline Singleton value & Fan speed & $\begin{array}{l}\text { Fan spinning } \\
\text { time }\end{array}$ \\
\hline $\mathrm{S}_{1}$ & 0 & 0 \\
\hline $\mathrm{S}_{2}$ & 0 & 0 \\
\hline $\mathrm{S}_{3}$ & 0.25 & 0.25 \\
\hline $\mathrm{S}_{4}$ & 0.5 & 0.5 \\
\hline
\end{tabular}

Rule base block for the designed model of air conditioning system contains lookup table, it consists of rules which are design for modeled. Two comparators, two detectors and two decoders, these detectors and decoders tell about the region maps by the input variable and response of fuzzy set to these variable. Comparator takes information's from detectors and decoders and gives the singleton values, as exposed in the Fig. 7.

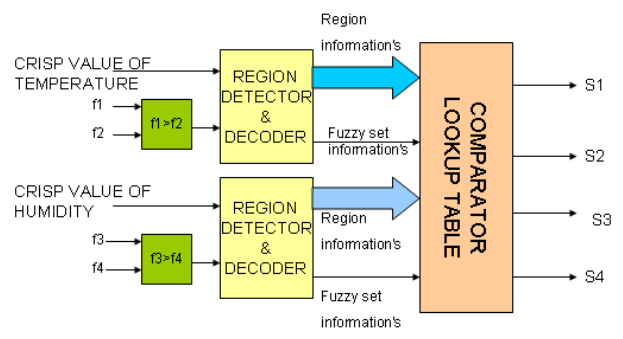

Fig. 7. Arrangement of rule base

Crisp values of output are obtained by defuzzification. There are many methods used for defuzzification e.g. (MOM) mean of maximum. (SOM) smallest of maximum (LOM) left of maximum etc.

The method use in this paper for defuzzification is(COA) center of average whose mathematical form is

$$
\sum_{i} S i \times R i / \sum R i
$$

where $\quad i=1,2,3,4$ 
This system takes eight inputs to each defuzzifier four from inference engine i.e. $R_{1}, R_{2}, R_{3}$ and $R_{4}$ and four from the rule base i.e. $S_{1}, S_{2}, S_{3}$ and $S_{4}$ and gives the crisp value of output fan speed and fan spinning time. MATLAB simulation result for this system are shown in the Fig. 8.

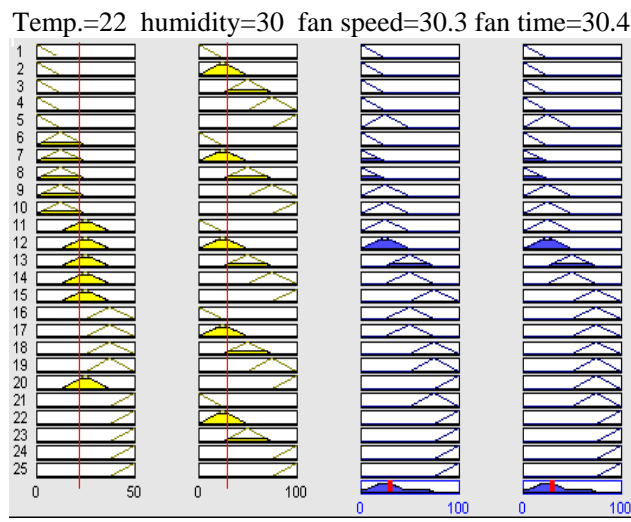

Fig. 8. Simulation results

Table VIII below shows the output defuzzified values for fan speed and fan spinning time from MATLAB simulation and also the defuzzified values from manual calculation corresponding to the input variable temperature $=22^{\circ} \mathrm{C}$ and humidity $=30$

\begin{tabular}{|c|c|c|}
\hline & Fan speed & $\begin{array}{l}\text { Fan spinning } \\
\text { time }\end{array}$ \\
\hline $\begin{array}{l}\text { MATLAB simulation } \\
\text { result }\end{array}$ & 30.3 & 30.4 \\
\hline $\begin{array}{c}\text { Manual calculated } \\
\text { values }\end{array}$ & 30 & 30 \\
\hline
\end{tabular}

\section{RESULTS DISCUSSION}

Fig. 8(a) shows that the temperature and fan speed are directly proportional to each other and fan speed is independent of humidity up to the value of 50 and then gradually increased with humidity

Fig. 8 (b) below shows that the temperature and fan spinning time are directly proportional to each other but humidity remains constant up to 50 and then increased with time

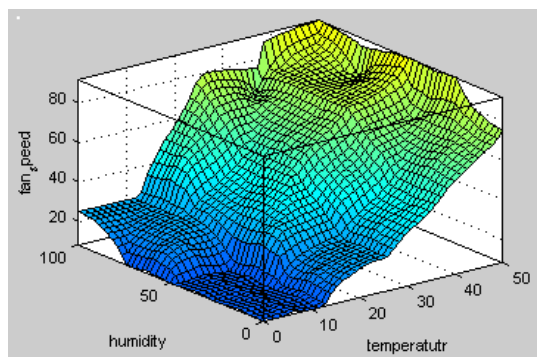

Fig. 8 (a). Plot between humidity temperature and fan speed

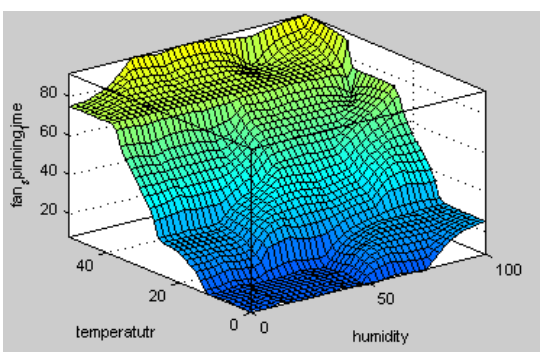

Fig. 8 (b). Plot between temperature humidity and fan spinning time

\section{CONCLUSION}

This paper presents the fuzzy time control discrete event model of autonomous air conditioning system and shows the effectiveness of the approach. Nowadays, the trend is to make systems, which use less energy, gives maximum efficiency. The proposed design fulfills these conditions and provides the conservation of energy due to its time dependency that operates the system for a specific period of time and gives the approximately same defuzzified values for MATLAB simulation and manual calculation. The system itself provides the base to design the fuzzy time control discrete event systems in future.

\section{REFERENCES}

[1] M. S. Khan and K. Benkrid, "A proposed grinding and mixing system using fuzzy time control discrete event model for industrial application," in Proc. Directory of Open Access Journals (DOAJ), Lecture Notes in Engineering and Computer Science, vol. 2175, 2009, pp. 1231-1236,

[2] M. S. Khan and K. Benkrid, "Design of liquids mixing control system using fuzzy time control discrete event model for industrial applications," in Proc. Directory of Open Access Journals (DOAJ), , World Academy of Science, Engineering and Technology, vol. 72 2010, pp. 545-553.

[3] M. S. khan, "Fuzzy time control modeling of discrete event system," in Proc. International Conference on Intelligent Automation and Robotics, U.S.A. ICIAL-51, WCECS 2008, pp. 683-688.

[4] E. F. Martinez, G. Magoulas, S. Chen, and R. Macredie, "Modeling human behavior in user-adaptive systems: Recent advances using soft computing techniques," Expert Syst. Appl. vol. 29, no. 2, 2005, pp. 320-329.

[5] M. Perkowitz and O. Etzioni, "Adaptive web sites," Commun ACM, vol. 43, no. 8, 2000, pp. 152-158.

[6] E. Kim, M. Park, and S. Ji, "A new approach to fuzzy modeling," IEEE trans. Fuzzy system, vol. 5, no. 8, 1997, pp. 328-337.

[7] S. I. Shakowat, "Development of fuzzy logic controller algorithm for air conditioning system," in Proc. ICSE 2006, IEE.

[8] Y. C. HO, "Discrete event dynamic system analyzing complexity and Performance in the modern word," IEEE press, 1994.

[9] R. Tibshirani, T. Hastie, and J. Friedman, "The elements of statistical learning," Springer-Verlag, Heidelberg, 2001. J. P. Wilkinson, "Nonlinear resonant circuit devices," U.S. Patent 3624 12, July 16, 1990.

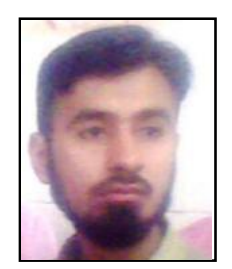

Syed Fazil Bin Farukh is received M.S. degree in the field of electronics engineering from faculty of Engineering and Technology, International Islamic University Islamabad. $\mathrm{He}$ is currently availing a research fellowship at The GC University, Lahore, Pakistan and completed his M.S thesis in the field of control systems: with title "industrial application of fuzzy time control discrete event system“. His research interests include control systems design and industrial applications.

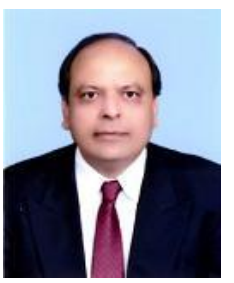

M. Saleem Khan is a director of computer science dept. at GC University Lahore, Pakistan. He completed his Ph.D. thesis in the field of control systems: design, simulation and analysis in local and distributed environment. He contributed his services on various projects in the field of Advanced Electronics and Communication. His Research interests include control systems design and industrial applications. He promoted a large team of Electronics researchers and organized this field in his country. Mr. Khan had also been served as a senior scientific officer in a classified defence research organization in his country. 